\title{
ECOMORPHOLOGICAL INDICATORS OF FEEDING BEHAVIOR IN RECENT AND FOSSIL RAPTORS
}

\author{
FRITZ HERTEL \\ Department of Biology, University of California at Los Angeles, \\ Los Angeles, California 90024, USA
}

\begin{abstract}
Modern raptors feed predominantly on animals and exhibit a wide range of feeding behaviors and prey preferences. The following six ecomorphs, based on feeding preferences served to classify members from all families of diurnal birds of prey: (1) avivores, which feed primarily on avian prey; (2) mammalivores, which feed primarily on mammalian prey; (3) herpetivores, which feed primarily on reptiles and amphibians; (4) piscivores, which feed primarily on fishes; (5) scavengers, which are primarily carrion feeders; and (6) generalists, which are opportunistic feeders on all of the above prey and on invertebrates. A series of skull-based indices were created to reflect functional aspects of prey preferencescalculated from measures of the cranium, maxilla (beak) and mandible-and were analyzed separately and with all units combined. The same indices were determined for 13 raptor species, including some extinct genera unearthed from the Pleistocene Rancho La Brea tar pits in California. A discriminant function analysis was used to assess the functional predictability of the indices for the extant raptors and also to predict the ecomorphs of the fossils. Results indicate that all of the indices combined provide the best predictor of prey preferences, especially for scavengers and avivores. Cranial and mandibular indices provide a better resolution than maxillary indices when considering only isolated elements. Eleven fossil species were assigned to their dietary categories with high probabilities and two were less definitely classified. Received 28 February 1994, accepted 16 May 1994.
\end{abstract}

ECOMORPHOLOGY DESCRIBES the interrelationship between the functional morphology of organisms and their environment. It can be viewed as the environment shaping the design of the organism or the functional morphology of the organism determining its interaction with the environment (Wainwright 1991). Several workers have examined the correlation between aspects of morphology (e.g. wing, beak, and tarsus lengths) and ecological factors (e.g. habitat). These studies have included tropical frugivorous birds (Karr and James 1975), temperate scrub birds (Ricklefs and Travis 1980), grassland insectivores (Leisler and Winkler 1985), passerine communities (Miles et al. 1987), and North American kinglets (Keast and Saunders 1991). Other workers have used multivariate morphometrics to interpret the paleoecology of extinct penguins (Livezey 1989), boobies (Warheit 1992), anatids (Livezey 1993a), and raphids (Livezey 1993b).

Raptors (defined here as diurnal birds of prey, including vultures) exhibit a variety of prey preferences. For this analysis, species were assigned to one of six ecomorphological categories (ecomorphs) based on their primary diet: (1) avivores, which feed predominantly on avian prey; (2) mammalivores, which feed primarily on mammalian prey; (3) herpetivores, which feed primarily on reptiles and amphibians; (4) piscivores, which feed primarily on fishes; (5) scavengers, which are primarily carrion feeders; and (6) generalists, which are more generalized feeders on all of the above prey, including invertebrates.

The dietary categories are distributed among five families (Grossman and Hamlet 1964, Brown and Amadon 1968, Kemp and Crowe 1990, Sibley and Ahlquist 1990, Hoyo et al. 1994). Avivores, represented by falcons (Falconidae) and accipiters (Accipitridae), typically pursue and feed on avian prey. Mammalivores, which include most hawks and eagles (Accipitridae), prey on mammals from rodents to small ungulates. Herpetivores include the Secretarybird (Sagittarius serpentarius; Sagittariidae), the Laughing Falcon (Herpetotheres cachinnans; Falconidae), and harrier eagles (Accipitridae). Piscivores consist of the Osprey (Pandion haliaetus; Pandionidae) and certain genera of fish eagles (Haliaeetus and lchthyophaga; Accipitridae). Scavengers were considered those species that primarily feed on carrion, given that most animals will scavenge opportunistically or under conditions of low food 
availability. This group included Old World vultures (Accipitridae) and New World vultures (Vulturidae auct. Cathartidae), both of which are obligate scavengers, and caracaras (Falconidae); caracaras are primarily scavengers, although they also kill small animals. Generalists include the kites, which feed on a variety of small vertebrates, but also insects and other invertebrates. The species of kites in this study represent three or four different lineages within the Accipitridae (e.g. Elaninae, Perninae, Milvinae sensu Grossman and Hamlet 1964; elani, pemi, milvi, accipitri sensu Kemp and Crowe 1990).

Differences in cranial morphology among the aforementioned groups should be expected in view of their feeding preferences. Avivores may show different adaptations in skull morphology given that birds generally have thinner skin than most other vertebrates and may be easier to tear. Scavengers often feed in large groups and on nonstruggling prey that often are much larger than themselves and, thus, may show adaptations that reflect feeding rapidly compared with other raptors. Generalists might be expected to overlap with many of the other ecomorphs given their more generalized diet. Other potential differences might be a result of killing modes among raptors. Unlike most other raptors, falcons kill primarily with their beaks; they usually apprehend prey using their feet and, subsequently, sever the vertebral column with their beak (Brown and Amadon 1968, Cade 1982). Scavengers rarely if ever kill, and all other raptors kill prey primarily with their feet. Both the falcons and the scavengers might be expected to exhibit stronger beaks given a greater reliance on their beaks for prey acquisition.

Correlations between skull morphology and dietary preference among these raptors were investigated and also used to predict the preferred diets of raptor species from the Late Pleistocene Rancho La Brea tar pits in California. These deposits contain a well-preserved avifauna with a large number of predatory and scavenging species.

The primary purpose was to determine the relative predictive value of the selected variables (described below) for different skull components, and their usefulness regarding questions of function in extant and extinct raptors. Information from this study can lend insight into the feeding behavior of extinct species and, thus, provide a basis for a better understanding of their paleoecology.

\section{METHODS}

Species selected.-Ninety raptor species were assigned to one of the six defined dietary categories: scavengers, avivores, herpetivores, piscivores, mammalivores, and generalists (Table 1). Many raptors feed on a variety of prey and may exhibit seasonal changes in their diets; however, species were classified as to their most typical diet. For example, most accipiters were classified as avivores because they typically prey on birds, even though some species may take some proportion of mammalian prey. All assignments were based on work by Grossman and Hamlet (1964), Brown and Amadon (1968), and Hoyo et al (1994).

Fossil species included raptors represented by skull remains from the Pleistocene Rancho La Brea tar pits in California (Table 1); other species are represented only by postcranial elements (e.g. falcons and accipiters). Of the 13 fossil species examined, four are still extant: Golden Eagle (Aquila chrysaetus), Bald Eagle (Haliaeetus leucocephalus), Turkey Vulture (Cathartes aura), and California Condor (Gymnogyps californianus). Two species, the Errant Eagle (Neogyps errans) and American Neophron (Neophrontops americanus), are considered Old World vultures in the New World Neogyps errans was originally described as an eagle with some vulturine habits (Howard 1932), but is typically referred to as a vulture (e.g. Rich 1980a, Harris and Jefferson 1985); it may have been a facultatively scavenging eagle. Other raptors analyzed from Rancho La Brea included: Grinnell's Crested Eagle (Spizaetus grinnelli), Fragile Eagle (Buteogallus [Hypomorphnus] fragilis), Woodward's Eagle (Amplibuteo [Morphnus] woodwardi), La Brea Condor (Breagyps clarkii), Occidental Vulture (Coragyps occidentalis), La Brea Caracara (Polyborus prelutosus), and Merriam's Teratorn (Teratornis merriami; member of extinct family Teratornithidae with no living analogue).

Morphology. - Analyses were based on head skeletons, in part because bones are the primary clues available from the fossil record. The skull was examined as three separate units: the cranium, maxilla (beak), and mandible. Fossil skull remains often preserve as isolated parts; thus, it is useful to determine whether feeding behavior of extinct forms can be assessed from these parts separately. Specimens were analyzed based on 25 measurements. Seventeen indices or ratios were generated that reflect functional aspects of the skull and feeding behavior (Table 2, Fig. 1).

These indices fall into seven categories. Two categories concern the mechanical advantage of muscles involved in skull movement and in jaw opening and closing. For example, occipital crest distance estimates the leverage of the $M$. complexus that inserts along the occipital crest and elevates the head. Opisthotic distance represents the leverage of $M$. rectus capitus ventralis that inserts at the opisthotic process and primarily moves the head laterally. Similarly, postar- 
TABLE 1. Species used in analyses. Number of specimens indicated in parentheses. For fossils, sample sizes indicate numbers of crania, maxillae, and mandibles, respectively. Extinct species identified by $\dagger$.

\section{Avivores \\ Accipitridae: Accipiter bicolor (3), A. badius (4), A. melanoleucus (1), A. minullus (1), A. striatus (4), A. tachiro (1), A. virgatus (1), Melierax gabar (1). \\ Falconidae: Falco biarmicus (1), F. cuvierii (2), F. femoralis (5), F. peregrinus (8), F. rufigularis (8), F. rupicoloides (1), Micrastur semitorquatus (6).}

\section{Mammalivores}

Accipitridae: Harpia harpyja (5), Aquila pomarina (1), A. rapax (5), A. wahlbergi (1), A. verreauxii (1), Buteogallus urubitinga (1), B. [Heterospizas] meridionalis (5), Hieratus fasciatus (2), Parabuteo unicinctus (1), Spizastur melanoleucus (2), Lophoaetus occipitalis (4), Buteo nitidus (4), B. magnirostris (3), B. albicaudatus (4), B. albonatus (1), B. auguralis (2), B. rufofuscus (4), Spizaetus cirrhatus (2), S. nipalensis (1), S. tyrannus (2), S. ornatus (4), Stephanoetus coronatus (5), Morphnus guianensis (1), Polmaetus bellicosus (1), Terathopius ecaudatus (4).

\section{Generalists}

Accipitridae: Haliastur indus (5), Pernis apivornis (4), Elanus caeruleus (5), Harpagus bidentata (5), Elanoides forficatus (6), Rostrhamus hamatus (1), R. sociabilis (5), Leptodon cayensis (2), Chondrohierax unicinctus (4), Ictinea plumbea (5), Milvus migrans (11), Aviceda cuculoides (1).

Sagittariidae: Sagittarius serpentarius (7).

\section{Herpetivores}

Falconidae: Herpetotheres cachinnans (3).

Accipitridae: Geranospiza caerulescens (6), Circaetus cinereus (1), C. gallicus (1), C. cinerascens (1), Spilornis cheela (5).

\section{Piscivores}

Pandionidae: Pandion haliaetus (3).

Accipitridae: Haliaeetus leucogaster (6), H. vocifer (3), Ichthyophaga humilis (1), I. ichthyaetus (1), Busarellus nigricollis (5).

\section{Scavengers}

Vulturidae (auct. Cathartidae): Vultur gryphus (7), Gymnogyps californianus (8), Sarcorhamphus papa (9), Coragyps atratus (8), Cathartes melambrotus (4), C. aura (10), C. burrovianus (5).

Accipitridae: Aegypius monachus (3), Sarcogyps calva (2), Torgos tracheliotus (5), Trigonoceps occipitalis (4), Gyps fulvus (2), G. rueppelli (2), G. coprotheres (3), G. africanus (8), G. bengalensis (2), G. himalayensis (1), G. indicus (1), Necrosyrtes monachus (5), Neophron percnopterus (4), Gypaetus barbatus (4).

Falconidae: Polyborus plancus (6), Daptrius ater (5), D. americanus (1), Milvago chimachima (9).

\section{Fossils}

Vulturidae (auct. Cathartidae): Breagyps clarkii $(5,4,1)$, Gymnogyps californianus $(29,20,8)$, Coragyps occidentalis $\dagger(17,9,1)$, Cathartes aura $(3,3,1)$.

Teratornithidae: Teratornis merriami $\dagger(9,6,2)$.

Accipitridae: Neogyps errans $\dagger(3,7,4)$, Neophrontops americanus $\dagger(4,8,1)$, Aquila chrysaetus $(16,21,15)$, Haliaeetus leucocephalus $(6,6,5)$, Buteogallus fragilis $\dagger(4,3,2)$, Amplibuteo woodwardii $\dagger(2,2,1)$, Spizaetus grinnelli $\dagger$ $(4,2,1)$.

Falconidae: Polyborus prelutosus $\dagger(7,1,1)$.

ticular length estimates the mechanical advantage of M. depressor mandibulae in jaw opening, and coronoid distance estimates that of the adductor complex inserting on the coronoid process (surangular) in jaw closing. The distance from the center of rotation (jaw joint or occipital condyle) to these muscle insertions should give an estimation of their relative mechanical advantages; inserting relatively farther from the center of rotation suggests a greater mechanical advantage for the muscle, assuming the out-lever remains the same (Hildebrand 1988). Two sets of ratios were used to estimate the shape and robustness of the mandible, respectively. Robustness of the ramus was examined by its cross-sectional shape at the narrowest point (ramus shape), and that of the mandibular sym- physis was estimated by its shape (symphysis shape) and relative length (symphysis length); mandibular shape was estimated by the angular spread of the rami with the anterior tip of the mandible as the vertex (converted to radians; mandibular shape). Maxillary length and shape, described by five ratios, were shown previously to correspond to feeding differences among vultures in different communities (Hertel 1992, 1994). Two indices were potential sensory/neural indicators, estimates of orbital diameter and foramen magnum diameter.

Measurements were taken with digital calipers (mm). All analyses were done using the SYSTAT statistical package (Wilkinson 1988).

Data analysis. - The data set consisted of values for 
TABLE 2. Indices based on skull measurements (letters refer to measurements depicted in Fig. 1).

\begin{tabular}{|c|}
\hline Cranium \\
\hline $\begin{array}{l}\text { 1. Skull shape }(c / a) \text {. -Skull width (at paroccipitals)/skull length (beak tip to supraoccipital). } \\
\text { 2. Opisthotic distance }(e / a) \text {. - Distance from occipital condyle to opisthotic process/skull length. } \\
\text { 3. Occipital crest distance }(f / a) \text {. - Distance from occipital condyle to dorsal occiput/skull length. } \\
\text { 4. Orbital diameter }(h / a) \text {.-Orbital diameter/skull length. } \\
\text { 5. Foramen magnum diameter }(g / a) \text {. - Foramen magnum diameter/skull length. } \\
\text { 6. Foramen magnum angle }(z) \text {. - Angle between basicranium and foramen magnum }(\times 0.0175) \text {. }\end{array}$ \\
\hline Maxilla (Beak) \\
\hline $\begin{array}{l}\text { 7. Maxillary length }(j / a) \text { - -Maxillary length (from nasofrontal hinge to tip)/skull length. } \\
\text { 8. Tomial length }(k / j) \text {-Tomial length (from nares to tip)/maxillary length. } \\
\text { 9. Maxillary shape }(y / k) \text {.-Maxillary width/maxillary length. } \\
\text { 10. Maxillary depth }(l / m) \text { - - Maxillary depth/maxillary arch length. } \\
\text { 11. Maxillary curvature }(n / o) \text { - - Maxillary arch radius/maxillary chord. }\end{array}$ \\
\hline Mandible \\
\hline $\begin{array}{l}\text { 12. Coronoid distance }(r / q) \text {-Distance to coronoid from articular/length to articular from tip. } \\
\text { 13. Postarticular length }(s / p) \text {. - Length of postarticular process / total length. } \\
\text { 14. Symphysis length }(t / q) \text {. - Length of symphysis/length to articular from tip. } \\
\text { 15. Symphysis shape }(t / u) \text {. - Length of symphysis/depth of symphysis. } \\
\text { 16. Ramus shape }(v / w) \text {. - Least width of ramus/depth of ramus at same point. } \\
\text { 17. Mandibular shape }(x) \text {. - Angular spread of rami with tip of mandible as vertex }(\times 0.0175) \text {. }\end{array}$ \\
\hline
\end{tabular}

the 17 indices for all individuals within the 90 extant species and the 13 fossil species. For most species, sample sizes were inadequate to determine sexual dimorphism; therefore, a species mean was generated for each index for use in subsequent analyses. Ratios help minimize the effect of body size, but may show allometric effects. However, they are better indicators of shape and mechanical advantages than residuals from a regression (Coruccini 1987). In allometric relationships, two species with the same residuals can have very different shapes. Least-squares regressions were used to investigate the allometric effects between each index and the best predictor of body size, namely skull length $\left(R^{2}=0.90\right.$ for regression of skull length on body mass). A Pearson product-moment correlation for each of the 17 variables and skull length was performed; all paired variables showed a relatively low correlation $(r \leq 0.73$ ). As a result, all were used in subsequent analyses because they only accounted for approximately one-half the variance in size ( $R^{2} \leq 0.50$ for regressions on skull length) and, therefore, should provide some functional information. The only exception was relative maxillary length $\left(R^{2}=0.76\right)$. A least-squares regression of this index on skull length showed that scavengers, avivores, and mammalivores generally plot outside the

Fig. 1. Features measured on skull as shown by Cathartes aura: (A) dorsal view; (B) occipital view; (C) lateral view; and (D) dorsolateral view of mandible. Measurements (corresponding to letters) described in Table 2.

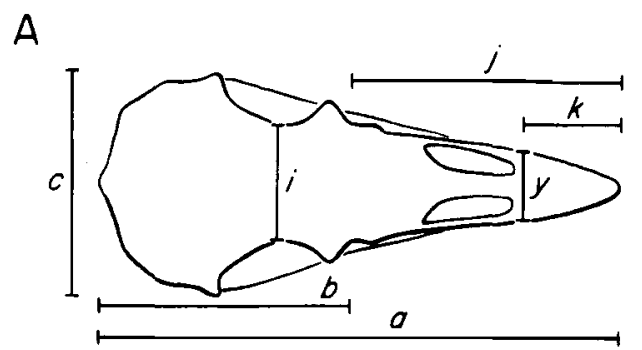

$B$
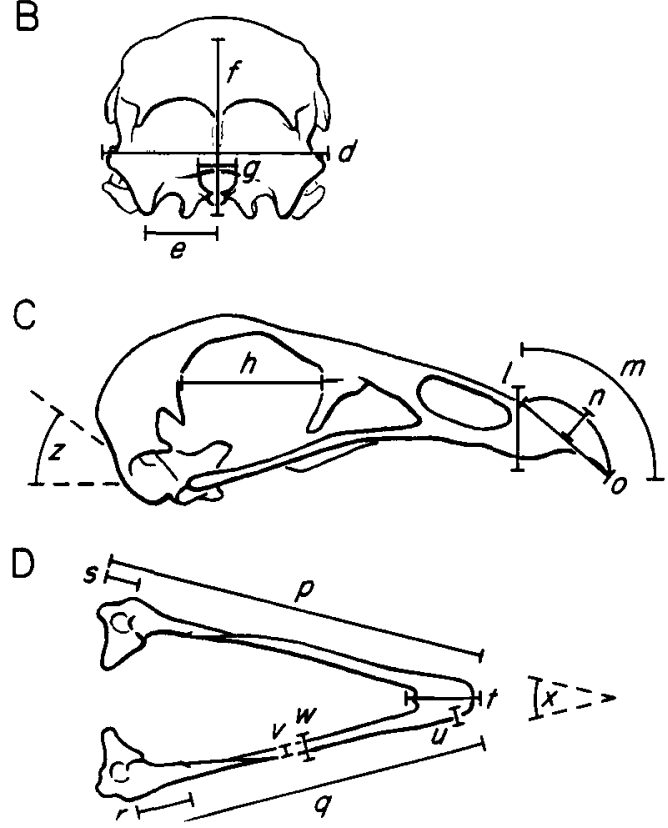


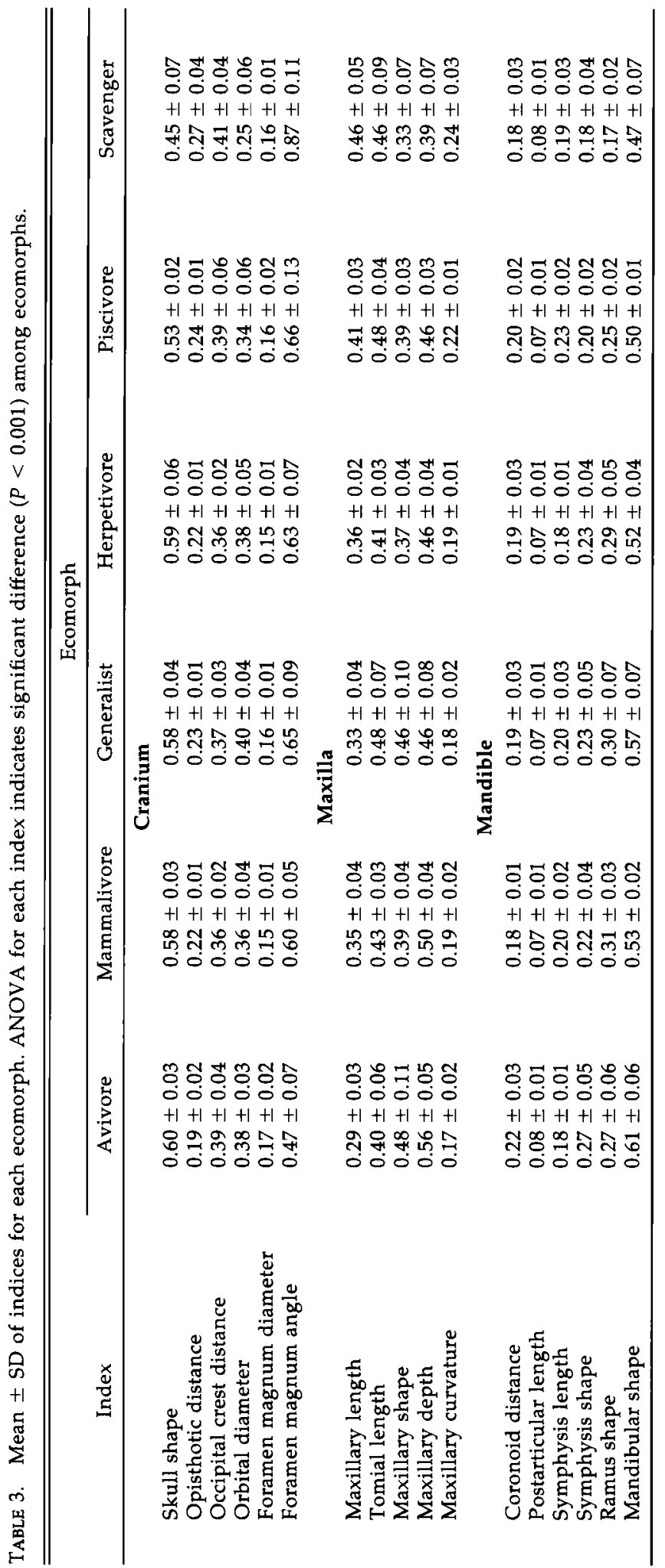


TABLE 4. Loadings on discriminant function axes based on cranial indices for all ecomorphs.

\begin{tabular}{lcccrrr}
\hline \hline & \multicolumn{5}{c}{ Axis } \\
\cline { 2 - 6 } \multicolumn{1}{c}{ Index } & \multicolumn{1}{c}{1} & \multicolumn{1}{c}{3} & \multicolumn{1}{c}{4} & 5 \\
\hline Skull shape & 0.21 & 0.23 & -1.03 & 1.11 & 0.22 \\
Opisthotic distance & -0.15 & 0.25 & 0.49 & -0.77 & -0.86 \\
Occipital crest distance & 0.16 & -0.80 & 0.12 & -0.42 & -0.51 \\
Orbital diameter & 0.31 & 0.60 & 1.28 & -0.62 & 0.24 \\
Foramen magnum diameter & 0.08 & -0.43 & 0.40 & 0.71 & -0.51 \\
Foramen magnum angle & -0.67 & 0.77 & 0.07 & 0.88 & 0.50 \\
Canonical correlation & 0.88 & 0.73 & 0.58 & 0.23 & 0.03 \\
Percent variance explained & 66.3 & 22.6 & 10.0 & 1.1 & 0.1 \\
\hline
\end{tabular}

95\% confidence limits. This suggests that maxillary length is not strictly size determined and so it was included in subsequent analyses.

A set of indices was generated that substituted skull length without the maxilla for total skull length, and produced similar results. The raw indices and arcsinetransformed data (to approximate normality, Sokal and Rohlf 1981) were analyzed separately and produced virtually identical results. Therefore, only results for the raw indices are presented. A discriminant function analysis (DFA) was performed to determine the effectiveness of the selected variables in predicting the different ecomorphs (Morrison 1967, Cooley and Lohnes 1971). This analysis calculates linear combinations of variables that maximize differences among groups determined a priori. Variables with the highest loadings contribute most in determining the separation among groups. The DFA also provides a classification of unknowns by determining their probability of assignment to each group. Fossil species were analyzed as unknowns in the DFA to predict their most probable ecomorphs. This a posteriori classification also was used to determine the validity of the selected variables as functional predictors for specimens of unknown ecomorphological classification.

\section{RESULTS}

The means and standard deviations of the indices for each dietary category are listed in Table 3. An ANOVA indicated a significant difference among the dietary categories for each variable $(P<0.001)$, suggesting that each index contributed some information to the analyses for at least one category. Therefore, all indices were included in the multivariate analyses.

Cranium. - The DFA of cranial variables showed that the foramen magnum angle was loaded the highest on axis 1, which accounted for $66 \%$ of the total intergroup variance in cranial indices (Table 4). Scavengers are distinguished from other ecomorphs by having a greater angle between the foramen magnum and the basicranium compared with other raptors, especially avivores (Table 3, Fig. 2). In addition to foramen magnum angle, occipital distance and orbital diameter were highly loaded on axis 2, which accounted for $23 \%$ of the intergroup variance (Table 4 ). Scavengers have a relatively greater occipital distance and smaller orbit compared to other raptors (Table 3, Fig. 2).

In general, avivores tend to be distinguished from other raptors by cranial indices; only 1 of 15 was assigned to another ecomorph a posteriori, as a generalist. The probabilities of group assignment for all but this one species ranged

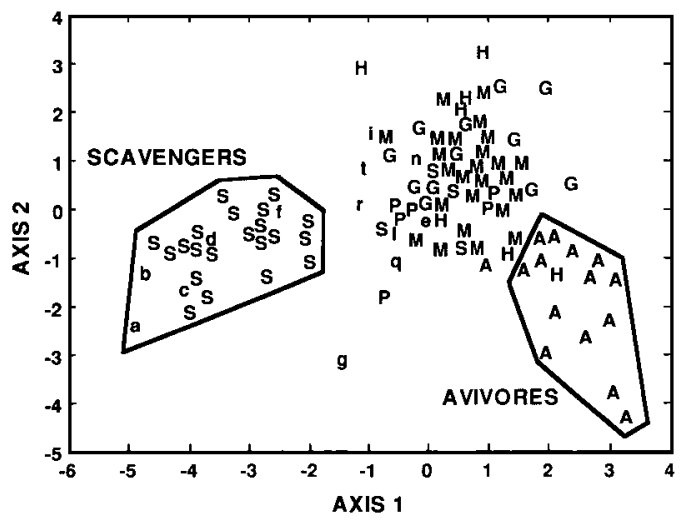

Fig. 2. Discriminant function analysis on cranial indices. Letters indicate: (A) avivores; $(G)$ generalists; $(\mathrm{H})$ herpetivores; $(\mathrm{M})$ mammalivores; $(\mathrm{P})$ piscivores; and (S) scavengers. Groups circumscribed include species classified within that group by the analysis. Lowercase letters represent fossil species from Rancho La Brea: (a) Breagyps clarkii; (b) Gymnogyps californianus; (c) Coragyps occidentalis; (d) Cathartes aura; (e) Neogyps errans; (f) Neophrontops americanus; (g) Teratornis merriami; (i) Aquila chrysaetus; (1) Haliaeetus leucocephalus; (n) Buteogallus fragilis; (q) Amplibuteo woodwardii; (r) Polyborus prelutosus; and (t) Spizaetus grinnelli. 
TABLE 5. Loadings on discriminant function axes based on maxillary indices for all ecomorphs.

\begin{tabular}{lccrrr}
\hline \hline & \multicolumn{5}{c}{ Axis } \\
\cline { 2 - 6 } \multicolumn{1}{c}{ Index } & \multicolumn{1}{c}{1} & \multicolumn{1}{c}{3} & \multicolumn{1}{c}{4} & 5 \\
\hline Maxillary length & 0.91 & 0.39 & 0.76 & 0.35 & 1.19 \\
Tomial length & 0.20 & 0.60 & -0.65 & 0.63 & -0.32 \\
Maxillary shape & 0.27 & 0.53 & 1.32 & -0.23 & 0.04 \\
Maxillary depth & -0.45 & -0.50 & 0.14 & 0.78 & 0.50 \\
Maxillary curvature & 0.05 & -0.81 & -0.06 & -0.18 & -1.23 \\
Canonical correlation & 0.88 & 0.54 & 0.36 & 0.20 & 0.08 \\
Percent variance explained & 85.2 & 10.0 & 3.7 & 1.0 & 0.2 \\
\hline
\end{tabular}

from 0.42 to 1.00 , with all but three greater than 0.83 . Scavengers also separated reasonably well from other groups with only the four caracaras assigned to different ecomorphs (two as mammalivores, one as a piscivore, and one as a herpetivore); the probabilities of group assignment for the vultures all exceeded 0.90 . The other four ecomorphs showed more overlap (Fig. 2). The overall classification success for cranial indices was $78 \%$.

Maxilla.-In the DFA based on maxillary indices alone, relative maxillary length was highly loaded on axis 1, which accounted for $85 \%$ of the variance among ecomorphs (Table 5). Scavengers separate well on this axis and generally have a relatively longer maxilla than other raptors, with the converse true for avivores (Table 3, Fig. 3). Maxillary curvature and tomial length were loaded the highest on axis 2 , which accounted for $10 \%$ of the variance among groups (Table 5); consequently, ecomorphs are not well separated along this axis. Scavengers have a more highly curved maxilla, and avivores have a short tomium compared to other raptors (Table 3, Fig. 3).

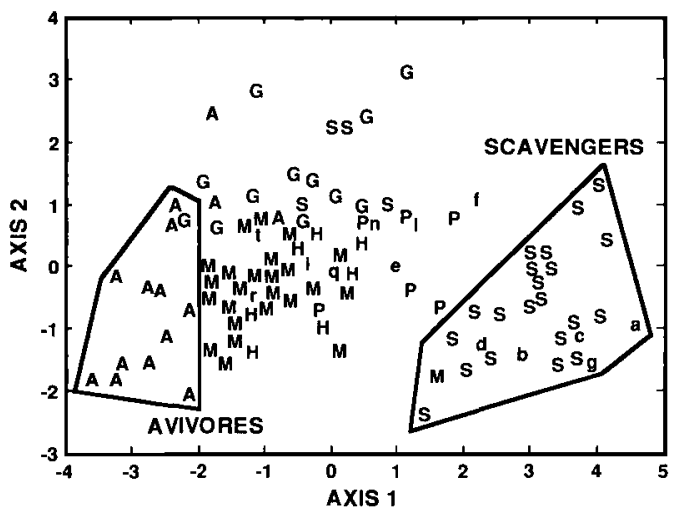

Fig. 3. Discriminant function analysis on maxillary indices (codes as in Fig. 2).
The ecomorph distinctions are less clear using only maxillary characters than for cranial indices. The four caracaras were assigned as generalists $(0.47<P<0.82)$ but all vultures were correctly assigned as scavengers $(P>0.80$ for all but three species). The analysis correctly assigned 12 of 15 avivores $(0.52<P<0.96)$. Again, there is more overlap among ecomorphs other than avivores and scavengers (Fig. 3), in which $60 \%$ were correctly assigned. The overall classification success for maxillary indices was $70 \%$.

Mandible.-The DFA on mandibular indices showed similar results for cranial and maxillary indices in that avivores and scavengers are the most distinct (Fig. 4). Ramus shape was highly loaded on axis 1 , which accounted for $72 \%$ of the variance among groups (Table 6); scavengers tend to have a ramus that is narrow relative to its depth compared to other raptors (Table 3, Fig. 4). Symphysis length, mandibular shape, and postarticular length were highly loaded on axis 2 , which accounted for $17 \%$ of the variance among groups (Table 6). Avivores generally have a wide mandible, whereas avivores and

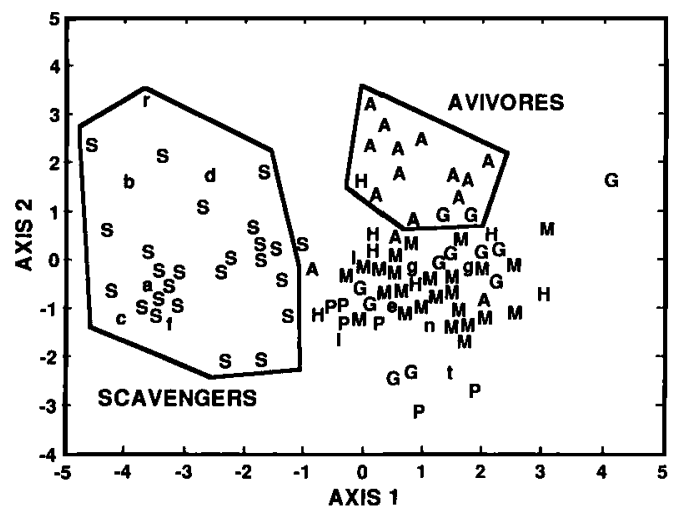

Fig. 4. Discriminant function analysis on mandibular indices (codes as in Fig. 2). 
TABLE 6. Loadings on discriminant function axes based on mandibular indices for all ecomorphs.

\begin{tabular}{lrrrrr}
\hline \hline & \multicolumn{5}{c}{ Axis } \\
\cline { 2 - 6 } \multicolumn{1}{c}{ Index } & \multicolumn{1}{c}{1} & \multicolumn{1}{c}{3} & \multicolumn{1}{c}{4} & 5 \\
\hline Coronoid distance & 0.06 & 0.22 & 0.75 & 0.75 & -0.25 \\
Postarticular length & -0.37 & 0.64 & -0.34 & 0.14 & 0.85 \\
Symphysis length & 0.43 & -0.72 & 0.72 & -0.13 & 0.23 \\
Symphysis shape & 0.33 & 0.06 & -0.41 & 0.32 & 0.11 \\
Ramus shape & 0.88 & -0.07 & -0.24 & 0.37 & 0.24 \\
Mandibular shape & 0.23 & 0.49 & 0.34 & -0.98 & -0.04 \\
Canonical correlation & 0.87 & 0.65 & 0.53 & 0.26 & 0.11 \\
Percent variance explained & 71.6 & 17.0 & 9.4 & 1.7 & 0.3 \\
\hline
\end{tabular}

scavengers have a short postarticular process, and herpetivores have a long symphysis (Table 3 , Fig. 4). Twelve of 15 avivores were correctly assigned $(0.32<P<0.98)$, scavengers had 24 of 25 correct assignments $(0.50<P<0.1 .00$ with $P>0.80$ for all but four species), herpetivores had 6 of 7 correctly assigned $(0.36<P$ $<0.63)$, and piscivores had all six correctly assigned $(0.46<P<0.99)$. As with the other elements, there is more overlap among ecomorphs other than avivores and scavengers (Fig. 4). The overall classification success for mandibular indices was $79 \%$.

Complete skull. - In the DFA analysis of all 17 indices, characters from each of the skull components (cranium, maxilla, and mandible) loaded highly on axis 1: foramen magnum angle, occipital crest distance, tomial length, maxillary shape, and symphysis length (Table 7). Axis 1 accounted for $62 \%$ of the variance among groups. Scavengers have a large foramen magnum angle, large occipital crest distance, and deeper ramus; avivores have a short tomium and a short mandibular symphysis compared to other raptors (Table 3, Fig. 5). On axis 2, which accounted for $16 \%$ of the intergroup differences, orbital diameter, occipital distance, maxillary length, and symphysis length were loaded the highest (Table 7). Avivores have a short maxilla, whereas scavengers have a combination of a deep mandibular ramus, small orbital diameter, and long maxilla (Table 3, Fig. 5).

Most of the highly loaded characters also were highlighted in the previous analyses of individual elements. However, the avivore and scavenger ecomorphs are more distinct using

TABLE 7. Loadings on discriminant function axes based on all skull indices for all ecomorphs.

\begin{tabular}{|c|c|c|c|c|c|}
\hline \multirow[b]{2}{*}{ Index } & \multicolumn{5}{|c|}{ Axis } \\
\hline & 1 & 2 & 3 & 4 & 5 \\
\hline Skull shape & 0.12 & 0.12 & -1.35 & 0.26 & 0.60 \\
\hline Opisthotic distance & 0.04 & 0.18 & 0.53 & -0.12 & 0.20 \\
\hline Occipital distance & -0.53 & -0.55 & -0.69 & -0.27 & -0.21 \\
\hline Orbital diameter & -0.05 & 0.59 & 0.65 & -0.52 & 0.94 \\
\hline Foramen magnum diameter & 0.20 & -0.39 & 0.52 & 0.11 & 0.02 \\
\hline Foramen magnum angle & 0.86 & 0.37 & 0.15 & 0.79 & 0.01 \\
\hline Maxillary length & 0.37 & 0.50 & 0.36 & -0.80 & 0.53 \\
\hline Tomial length & 0.50 & 0.14 & -0.05 & 0.48 & -0.24 \\
\hline Maxillary shape & 0.43 & 0.16 & 0.94 & -0.07 & -0.22 \\
\hline Maxillary depth & -0.35 & -0.33 & -0.36 & 0.04 & -0.34 \\
\hline Maxillary curvature & -0.02 & -0.14 & -0.50 & -0.12 & -0.06 \\
\hline Coronoid distance & -0.42 & 0.02 & 0.11 & -0.72 & 0.65 \\
\hline Postarticular length & 0.29 & -0.29 & -0.18 & 0.40 & 0.70 \\
\hline Symphysis length & -0.55 & 0.44 & 0.30 & -0.77 & -0.59 \\
\hline Symphysis depth & 0.14 & 0.20 & 0.07 & 0.29 & 0.10 \\
\hline Ramus shape & -0.51 & 0.33 & -0.01 & 0.11 & -0.24 \\
\hline Mandibular shape & -0.10 & -0.19 & 0.91 & 0.26 & -0.66 \\
\hline Canonical correlation & 0.94 & 0.81 & 0.77 & 0.65 & 0.50 \\
\hline Percent variance explained & 62.1 & 15.9 & 12.7 & 6.5 & 2.9 \\
\hline
\end{tabular}




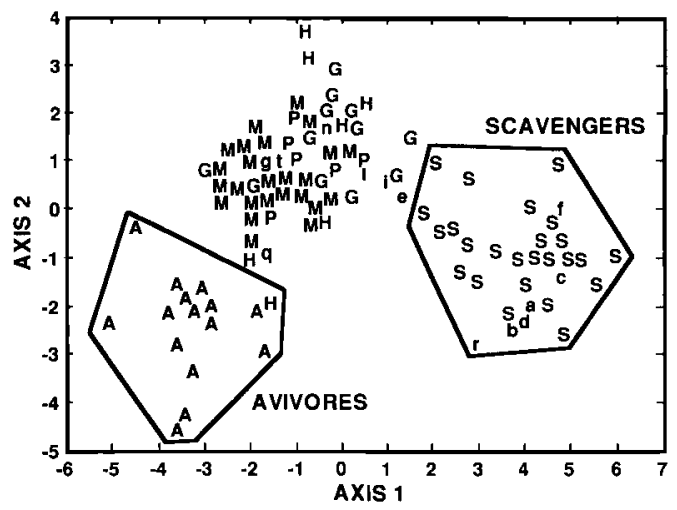

Fig. 5. Discriminant function analysis on all skull indices (codes as in Fig. 2).

all variables; with one exception, only species assigned a priori as a scavenger or avivore were classified as such (Fig. 5). Classification success was as follows: all 26 scavengers $(0.77<P<$ 1.00 , with $P>0.90$ for all but 2 species); all 17 avivores $(P>0.92) ; 5$ of 6 piscivores $(P>0.98)$; 4 of 7 herpetivores $(P>0.94) ; 11$ of 12 generalists $(P>0.95$ for all but 1 species); and 23 of 25 mammalivores $(0.57<P<0.99)$. The overall classification success was $92 \%$. Cross-validation analyses were done for species that were correctly assigned using all skull indices; results showed a $90 \%$ correct classification (77 of 84 ); most reassignments were among the generalists and mammalivores.

Secondary analysis. - The avivore and scavenger ecomorphs were the most distinct in all analyses and their inclusion may have minimized differences within the other four ecomorphs by accounting for most of the variance. To ascertain whether the indices were effective at discriminating mammalivores, piscivores, herpetivores and generalists from each other, the data were reanalyzed without the avivores and scavengers.

When all skull characters are used, the four groups appear fairly distinct (Fig. 6). Occipital crest distance and mandible width loaded the highest on axis 1, which accounted for $71 \%$ of the variance among groups (Table 8 ). Generalists tend to have a relatively wide mandible compared with herpetivores, mammalivores, and piscivores (Table 3, Fig. 6), and piscivores have a large occipital crest distance. Piscivores and mammalivores separate most from the others on axis 2, which accounted for $19 \%$ of the

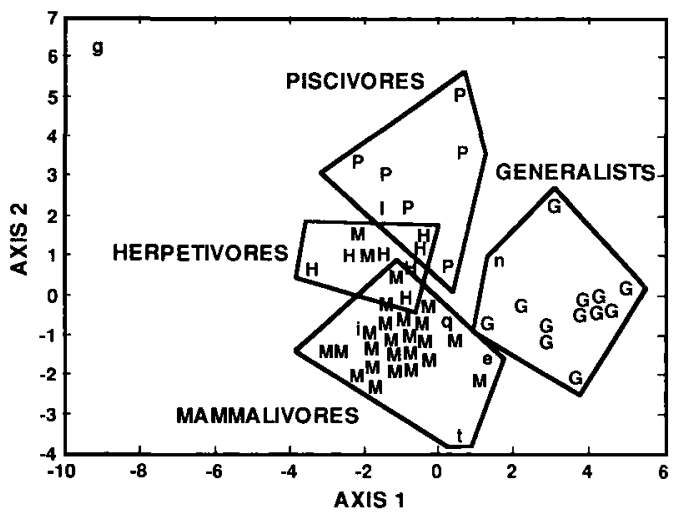

Fig. 6. Discriminant function analysis on all skull indices without avivore and scavenger ecomorphs (codes as in Fig. 2).

variance among groups (Table 8). Piscivores have a small orbit, long tomium, and long maxilla; mammalivores have a deep maxilla and short coronoid distance compared with other groups (Table 3, Fig. 6). All piscivores were correctly assigned ( $P>0.95$ for all but one species), as were all herpetivores $(P>0.93)$, all generalists ( $P>0.98$ for all but two species), and 23 of 25 mammalivores $(0.70<P<1.00)$.

Fossil raptors. - A classification analysis for the fossil raptors was generated for the total set of indices as well as for each subset. Group assignments were not always consistent; therefore, the probabilities of ecomorph assignment are listed only for the total set of skull indices (Table 9). Of the 13 fossil species analyzed, only five were assigned to the same ecomorph in all analyses: Breagyps clarkii, Gymnogyps californianus, Cathartes aura, Coragyps atratus, and Neophrontops americanus (all vultures) as scavengers. Four species assignments were supported by all but one analysis: Haliaeetus leucocephalus and $\mathrm{Bu}$ teogallus fragilis as piscivores by all but the cranial indices $(P>0.80$, and $0.42<P<0.69$, respectively); Spizaetus grinnelli as a mammalivore by all but the mandibular indices $(P>$ $0.70)$; and Neogyps errans as a mammalivore by all but the maxillary indices $(0.46<P<0.60)$. Aquila chrysaetus and Amplibuteo woodwardi were assigned as mammalivores based on analyses of all indices and cranial indices $(P>0.80)$. $P o-$ lyborus prelutosus was predicted as a scavenger by maxillary indices and all indices combined $(P>0.89)$. Teratornis merriami was predicted as a piscivore by cranial indices and all indices combined $(P>0.99)$. 
TABLE 8. Loadings on discriminant function axes based on all skull indices for herpetivore, mammalivore, piscivore, and generalist ecomorphs.

\begin{tabular}{|c|c|c|c|}
\hline \multirow[b]{2}{*}{ Index } & \multicolumn{3}{|c|}{ Axis } \\
\hline & 1 & 2 & 3 \\
\hline Skull shape & -0.57 & -0.44 & 0.36 \\
\hline Opisthotic distance & 0.04 & 0.28 & 0.20 \\
\hline Occipital distance & -1.04 & 0.12 & 0.19 \\
\hline Orbital diameter & 0.16 & 0.71 & -0.65 \\
\hline Foramen magnum diameter & 0.88 & -0.06 & -0.08 \\
\hline Foramen magnum angle & 0.83 & -0.33 & -0.53 \\
\hline Maxillary length & 0.57 & 0.78 & -0.13 \\
\hline Tomial length & 0.41 & -0.65 & 0.27 \\
\hline Maxillary shape & 0.84 & 0.45 & 0.35 \\
\hline Maxillary depth & -0.72 & -0.70 & 0.21 \\
\hline Maxillary curvature & -0.54 & 0.20 & 0.12 \\
\hline Coronoid distance & -0.52 & 0.65 & -0.48 \\
\hline Postarticular length & 0.11 & 0.02 & -0.76 \\
\hline Symphysis length & 0.26 & 0.24 & 1.09 \\
\hline Symphysis depth & -0.06 & 0.04 & -0.46 \\
\hline Ramus shape & 0.23 & -0.42 & 0.26 \\
\hline Mandibular shape & 1.45 & -0.25 & 0.29 \\
\hline Canonical correlations & 0.90 & 0.80 & 0.70 \\
\hline Percent variance explained & 71.3 & 18.7 & 10.0 \\
\hline
\end{tabular}

In the secondary analysis with no scavenger or avivore ecomorphs included, the nonscavenging species were reanalyzed to determine their assigned ecomorphs. Those fossil species that were predicted previously as scavengers were eliminated from this analysis. Results from all skull indices showed that of the remaining species, all but one were classified as they had been in the previous analysis that included all species: Teratornis merriami, Haliaeetus leucocephalus, Spizaetus grinnelli, Aquila chrysaetus, Neogyps errans, and Amplibuteo woodwardi. Buteogal- lus fragilis was predicted as a generalist rather than a piscivore (Table 9).

\section{Discussion}

Extant raptors. - In general, the indices for individual skull elements were good predictors of ecomorphological groups, especially scavengers and avivores. Mandibular and cranial indices showed the highest probabilities among species for group assignment followed lastly by maxillary indices. I assumed that features of the

TABLE 9. Probabilities $(P)$ of assignment for two most likely ecomorphs (1 and 2) of fossil species predicted by discriminant function analysis for all skull indices. Ecomorph 3 is most likely classification based on analysis for all skull indices excluding avivore and scavenger ecomorphs. Extinct species indicated by $\dagger$.

\begin{tabular}{|c|c|c|c|}
\hline \multirow[b]{2}{*}{ Species } & \multicolumn{3}{|c|}{ Ecomorph } \\
\hline & 1 & 2 & 3 \\
\hline Breagyps clarkit & Scavenger(1.00) & - & - \\
\hline Gymnogyps californianus & Scavenger(1.00) & - & - \\
\hline Coragyps occidentalis $\dagger$ & Scavenger(1.00) & - & - \\
\hline Cathartes aura & Scavenger $(1.00)$ & - & - \\
\hline Neogyps erranst & Mammalivore(0.60) & Scavenger( 0.35$)$ & Mammalivore(0.52) \\
\hline Neophrontops americanus $\dagger$ & Scavenger(1.00) & - & - \\
\hline Teratornis merriamit & Piscivore(1.00) & - & Piscivore $(0.66)$ \\
\hline Aquila chrysaetus & Mammalivore(0.95) & - & Mammalivore(0.97) \\
\hline Haliaeetus leucocephalus & Piscivore $(0.97)$ & - & Piscivore $(0.98)$ \\
\hline Buteogallus fragilis† & Piscivore $(0.69)$ & Generalist $(0.22)$ & Generalist $(0.87)$ \\
\hline Amplibuteo woodwardi $\dagger$ & Mammalivore $(0.80)$ & Avivore $(0.11)$ & Mammalivore $(0.92)$ \\
\hline Polyborus prelutosus $\dagger$ & Scavenger(0.99) & - & - \\
\hline Spizaetus grinnelli† & Mammalivore(0.99) & - & Mammalivore(0.99) \\
\hline
\end{tabular}


maxilla would be most informative given that they are often greatly modified for dietary differences; however, the opposite was true. Few maxillary indices were highly loaded in the DFA. Not surprisingly, using all skull indices proved best at separating each ecomorph in the discriminant space. In general, the individual skull elements were least effective in their ability to distinguish mammalivores, herpetivores, and generalists. Avivores and scavengers were most consistently distinguished, piscivores were distinguished to a lesser degree. For every index, avivores or scavengers had either the highest or lowest value, and in most cases they differed greatly (Table 3 ).

The different ecomorphs, especially avivores and scavengers, have adaptations that reflect feeding preferences, warranting a discussion of the highly loaded variables (for variable means, see Table 3). Vultures typically stand in a hunched pose and, when feeding, they often pull straight back such that the neck, maxilla, and head are more or less in a direct line with the line of action of the pulling force (pers. obs.). The large angle between the foramen magnum and the basicranium probably reflects this behavior (Fig. 1C, measurement $Z$ ), and also reflects the angle at which the spinal column enters the braincase. A large angle also is typical for caracaras. In contrast, other raptors tend to pull more at right angles to their prey, such that the angle between the neck and skull is approximately $90^{\circ}$. Scavengers also have a relatively narrow skull, but the distances to the opisthotic and occipital crest are comparatively longer than in other raptors. This reflects an increased mechanical advantage of muscles moving the head both laterally and dorsoventrally, and consequently enhances the ability to twist meat from a carcass. Unlike most other raptors, vultures generally feed on prey much larger in body mass than themselves and often feed in large numbers; the ability to rip large chunks from a carcass rapidly, therefore, would be selectively advantageous. Scavengers also have a relatively small orbital diameter; apparently selection has not favored greater visual acuity for discovering large, immobile prey. In contrast, other raptors often hunt cryptic, mobile prey and probably require enhanced vision.

Scavengers have a relatively long, narrow, shallow, highly curved maxilla compared to other raptors, especially avivores, which show the converse. An analogy might be drawn between a similar-sized meathook and stapler (or church-key can opener): one is long, thin and curved for hooking or slicing big chunks, and the other is short, robust and less curved for snipping small pieces and producing a strong bite.

Scavengers tend to have a deep, narrow ramus compared with other raptors (ramus width/ ramus depth). A deeper ramus would indicate an adaptation to greater loads in the dorsoventral direction and less resistance to lateral bending (Bock and Kummer 1968). This is supported by the low regression coefficient $\left(R^{2}=0.16\right)$ for a least-squares regression of this index on mandible length; it is not highly correlated with size (mandible length). Scavengers may experience greater loads in the dorsoventral direction of the mandible because they often feed on large prey and often in groups, where selection would favor rapid consumption of their prey (Houston 1988, Hertel 1992). Those vultures with the deepest mandibular rami are primarily those species that congregate in large numbers at a carcass (e.g. griffons, Gyps spp.). Their narrow, deep ramus in combination with their comparatively shallow mandibular symphysis probably reflects an ability to control the loads they experience, given that they feed on carrion. A narrow ramus and a shallow symphysis are likely to be less resistant to twisting forces produced by struggling prey. Scavengers also have a narrow mandible, whereas avivores have the widest, a feature that correlates somewhat with skull width.

Caracaras are not as specialized as vultures in their scavenging behavior. Using all skull characters, they were predicted with high probabilities as scavengers. However, they plotted somewhat between the falcons and vultures (Fig. 6; low values on axis 1 for scavengers), supporting their morphological and functional divergence from a falconid ancestor. Indeed, they were not predicted as scavengers using cranial and maxillary characters separately.

Avivores generally show the converse of scavengers in their mean index values (Table 3). Avivores have a wide skull but a short distance to the opisthotic, reflecting less mechanical advantage for muscles involved in lateral twisting of the head. In addition to their short, wide maxillae, avivores also have a deep mandibular symphysis and long adductors compared to other raptors. A relatively deep sym- 
physis would be more resistant to dorsoventral bending and, therefore, would be stronger. A short maxilla in association with an adductor insertion farther from the jaw joint provides a greater mechanical advantage to the jaw adductors. A relatively wide maxilla is advantageous for grasping and crushing prey. Thus, a short, wide maxilla together with stronger adductors and a stronger symphysis would be advantageous for a killer that must subdue its struggling prey. Falcons kill with their maxillae by severing or crushing the vertebral column of their victims, and accipiters have been observed to commence feeding on their prey prior to the victim's death (pers. obs.).

Without the avivore and scavenger ecomorphs, piscivores and generalists separated best in the discriminant space (Fig. 7). Functional interpretations for these differences are unclear. Many of the index means for piscivores are similar to those of scavengers, suggesting that feeding on scaled fishes might result in selection for features resembling those for feeding rapidly on large carcasses. Perhaps selection has not resulted in functional differences in skull morphology for feeding on reptiles versus mammals. Many raptors that feed on grounddwelling prey apparently do not show strong feeding preferences; many species were difficult to classify because they fed equally on small mammals and reptiles (Brown and Amadon 1968, Hoyo et al. 1994). In cross-validation analyses, some species were classified differently when entered as unknowns in the analysis. This occurred primarily among mammalivores, herpetivores, and generalists. Another factor to consider is that herpetivores and piscivores were represented by fewer species in the analyses making them more difficult to define using the indices. Perhaps more species in these categories would provide a better resolution.

Interestingly, the aforementioned indices are functionally convergent given that they are typically exhibited by species from at least two families of raptors. This minimized the potential for phylogenetic bias in the analysis.

Fossil raptors. - Several species from La Brea are extant and so may help determine the utility of the functional indices in ecomorphological classifications. The New World vultures (Breagyps clarkii, Coragyps occidentalis, Gymnogyps californianus, Cathartes aura), the Old World vulture (Neophron percnopterus), and the La Brea Caracara (Polyborus prelutosus) were classified as scav- engers with very high probabilities. Haliaeetus leucocephalus was classified as a piscivore using all but the cranial indices, even in the secondary analysis (without avivores and scavengers). Likewise, Aquila chrysaetus was strongly predicted as a mammalivore. Because we know the dietary preferences of the extant species, results for these fossil species lend further credence to the reliability of the indices. The numerous remains of $A$. chrysaetus at the tar pits suggest that it scavenged frequently, perhaps more so than today; it is the most abundant avian species found at the tar pits.

Of the remaining extinct species, two have smaller extant congeners in more forested areas of South America. Spizaetus grinnelli was classified with a high probability as a mammalivore, as were its modern congeners; Buteogallus fragilis was classified with low probabilities as a piscivore and secondarily as a generalist. Most of its extant congeners are opportunistic feeders that feed to a large extent on fishes (Hoyo et al. 1994). Amplibuteo woodwardi was classified as a mammalivore by all skull indices and cranial indices alone, but as a piscivore by the other analyses; this genus has no living representatives.

Neogyps errans, the supposed Old World vulture, was not classified with high probabilities $(P<0.60)$. All skull indices led to its classification as a mammalivore, as did the secondary analysis (avivores and scavengers removed). This problematic species with no clear living analogue appears to be somewhat anomalous morphometrically, suggesting that it may have been a more generalized feeder, but apparently not an obligate scavenger or vulture.

Teratomis merriami, once thought to be a scavenger (Miller 1909), was later categorized as an active predator (Campbell and Tonni 1981) based on features of the quadrate/articular apparatus and mandibular spreading. My study supports the classification of this species as a predator; however, it was classified as a piscivore in all analyses but the maxillary and mandibular indices. The foot morphology of teratorns was not strongly raptorial (Campbell and Tonni 1983). Certain seabirds (e.g. frigatebirds, some terns) feed by plucking fish from the surface of the water with their beaks without landing on the water (Ashmole 1971). Perhaps teratorns fed in a similar manner in nearshore waters. The wing bones of teratorns are similar to those of condors (Campbell and Tonni 1983), but also sim- 
ilar in proportion to those of pelicans and the Bald Eagle (pers. obs). Teratorns may have been coastal inhabitants that occasionally migrated inland (e.g. seasonally), or perhaps bred farther inland. The Pacific coastline during the Pleistocene was closer to Rancho La Brea than at present; the two localities are now separated by about $18 \mathrm{~km}$ (Woodward and Marcus 1973). The abundant teratorn remains at Rancho La Brea also suggest this species may have been a facultative scavenger, as is the Bald Eagle. Interestingly, no gull remains (Larus spp.) have been found at the tar pits; perhaps gulls were excluded by teratorns or other facultative scavengers.

The number of species of large diurnal raptors in western North America was greater during the Pleistocene than the present (Van Valkenburgh and Hertel in press). Moreover, there was twice the number of scavengers ( 6 or 7 vs. 3) and large (tarsus $>75 \mathrm{~mm}$ ) raptors (12 vs. 5 or 6) during the Pleistocene. This difference probably reflects a greater abundance and diversity of prey species during the Pleistocene (Martin and Steadman 1984, McDonald 1984, Van Valkenburgh and Hertel in press). The entrapment of predatory species at Rancho la Brea also suggests strongly that many raptors scavenged opportunistically.

In summary, the selected functional indices appear useful for discriminating the preferred diets of most raptors and, thereby, help to interpret the paleoecology of extinct species. The avivore and scavenger ecomorphs were most readily distinguished from other groups, and so were piscivores to a lesser degree. More work is necessary on raptors that are not bird eaters or obligate scavengers; perhaps dietary preferences exhibited by ecomorphs other than avivores or scavengers are not manifested by dramatic differences in skull morphology. Certain skull elements are better functional predictors than others, namely the mandible and cranium. over the maxilla, but taken together they provide a plausible discrimination of the selected raptor ecomorphs.

\section{ACKNOWLEDGMENTS}

Specimens of extant species were housed at the American Museum of Natural History (AMNH), the U.S. National Museum (USNM), the Natural History Museum of Los Angeles County (LACM), the University of California, Berkeley, Museum of Vertebrate
Zoology (UCMVZ), San Diego Natural History Museum (SDNH), University of Kansas Museum of Natural History (KUNHM), Louisiana State University Museum of Natural Science (LSUMZ), Natural History Museum, London (BMNH), and the University of California, Los Angeles, Bird and Mammal collection (UCLA). Fossil specimens were housed at the University of California, Berkeley, Museum of Vertebrate Paleontology (UCMVP) and the George C. Page Museum in Los Angeles (PAGE). I thank: W. Anyonge, D. Buth, E. Geffen, D. Jacobs, T. Rasmussen, F. James, and especially B. Van Valkenburgh for improving this paper; the late $B$. Obst for his help and encouragement in the early stages of this work; B. Livezey, T. Crowe, G. Schnell, and an anonymous reviewer for critical reviews; $S$. Olson (USNM), Mary Le Croy (AMNH), T. Demere (SDNH), J. V. Remsen (LSUMZ), H. Hutchison (UCMVP), D. Sakurai (UCMVZ), K. Campbell (LACM), B. Chandler (KUMNH), P. Colston (BMNH), G. Jefferson, E. Scott, and C. Shaw (PAGE), and J. Northern (UCLA) for their curatorial assistance. This work was funded in part by Sigma Xi and a Frank M. Chapman Memorial Grant from the American Museum of Natural History.

\section{LITERATURE CITED}

AsHmole, P. N. 1971. Sea bird ecology and the marine environment. Pages 224-286 in Avian biology, vol. 1 (D. S. Farner and J. R. King, Eds.). Academic Press, New York.

BOCK, W. J., AND B. KUMMER. 1968. The avian mandible as a structural girder. J. Biomech. 1:89-96.

Brown, L., AND D. AMADON. 1968. Eagles, hawks, and falcons of the world. McGraw Hill, New York.

CADE, T. 1982. The falcons of the world. Cornell Univ. Press, Ithaca, New York.

CAmpBell, K. E., and E. TONNI. 1981. Preliminary observations on the paleobiology and evolution of teratorns (Aves: Teratornithidae). J. Vertebr. Paleont. 1:265-272.

Campbell, K. E., and E. TonNI. 1983. Size and locomotion in teratorns (Aves: Teratornithidae). Auk 100:390-403.

COOLEY, W. W., AND P. R. LoHNES. 1971. Multivariate data analysis. Wiley, New York.

CORRUCCINI, R. S. 1987. Shape in morphometrics: Comparative analyses. Am. J. Phys. Anthropol. 73:289-303.

Grossman, M. L., AND J. Hamlet. 1964. Birds of prey of the world. Bonanza Books, New York.

HARRIS, J. M., AND G. T. JEFFERSON (Eds.). 1985. Rancho La Brea: Treasures of the tar pits. Los Angel. Cty. Mus. Sci. Series, No. 36.

HERTEL, F. 1992. Morphological diversity of past and present New World vultures. Pages 413-418 in Papers in avian paleontology honoring Pierce Brodkorb (K. E. Campbell, Jr., Ed.). Los Angel. Cty. Mus. Sci. Series, No. 36. 
Hertel, F. 1994. Diversity in body size and feeding morphology in past and present vulture assemblages. Ecology 75:1074-1084.

HiLDEBRAND, M. 1988. Analysis of vertebrate structure, 3rd ed. John Wiley and Sons, New York.

Houston, D. C. 1988. Competition for food between Neotropical vultures in forests. Ibis 130:55-64.

HowARD, H. 1932. Eagles and eagle-like vultures of the Pleistocene of Rancho La Brea. Carnegie Inst. Washington Contrib. Paleontol. 429:1-82.

Hoyo, J., A. Elliott, and J. Sargatal (Eds.). 1994. Handbook of birds of the world, vol. 2. Lynx Editions, Barcelona, Spain.

KARR, R., AND F. JAMES. 1975. Eco-morphological configurations and convergent evolution in species and communities. Pages 258-291 in Ecology and evolution of communities (M. Cody and J. Diamond, Eds.). Harvard Univ. Press, Cambridge, Massachusetts.

KEAST, A., AND S. SAunders. 1991. Ecomorphology of the North American Ruby-crowned (Regulus calendula) and Golden-crowned ( $R$. satrapa) kinglets. Auk 108:880-888.

KeMP, A. C., AND T. M. CROWE. 1990. A preliminary phylogenetic and biogeographic analysis of the genera of diurnal raptors. Pages 161-175 in Vertebrates in the tropics (G. Peters and R. Hutterer, Eds.). Proc. Int. Symp. Vertebrate Biogeography and Systematics in the Tropics. Alexander Koenig Zool. Res. Inst. of Zool. Mus., Bonn, Germany.

LEISLER, B., AND H. WINKLER. 1985. Ecomorphology. Curr. Ornithol. 2:155-186.

LIVEZEY, B. C. 1989. Morphometric patterns in Recent and fossil penguins (Aves: Sphenisciformes). J. Zool. (Lond.) 219:269-307.

LIVEZEY, B. C. 1993a. Morphology of flightlessness in Chendytes, fossil seaducks (Anatidae: Mergini) of coastal California. J. Vertebr. Paleontol. 13: 185-199.

LIVEZEY, B. C. 1993b. An ecomorphological review of the Dodo (Raphus cucullatus) and Solitaire (Pezophaps solitaria), flightless Columbiformes of the Mascarene Islands. J. Zool. (Lond.) 230:247-292.

MARTIN, P. S., AND D.W. STEADMAN. 1984. Extinction of birds in the Late Pleistocene of North America.
Pages 466-477 in Quaternary extinctions (P. S. Martin and R. G. Klein, Eds.). Univ. Arizona Press, Tucson.

MCDonald, J. N. 1984. The reordered North American selection regime and late Quaternary megafaunal extinctions. Pages 404-439 in Quaternary extinctions (P. S. Martin and R. G. Klein, Eds.). Univ. Arizona Press, Tucson.

Miles, D. B., R. E. Ricklefs, AND J. Travis. 1987. Concordance of ecomorphological relationships in three assemblages of passerine birds. Am. Nat. 129:347-364.

MILLER, L. 1909. Teratornis, a new genus from Rancho La Brea. Univ. California Publ. Dep. Geol. 5:305317.

MORRISON, D. F. 1967. Multivariate statistical methods. McGraw-Hill, New York.

RICH, P. V. 1980a. "New World vultures" with Old World affinities. Contrib. Vertebr. Evol., Karger, Basel 5.

RICKLEFS, R. E., AND J. TRavis. 1980. A morphological approach to the study of avian community organization. Auk 97:321-338.

Sibley, C. G., AND J. E. Ahlquist. 1990. Phylogeny and classification of birds: A study in molecular evolution. Yale Univ. Press, New Haven, Connecticut.

SOKAL, R. R., AND F. J. RoHLF. 1981. Biometry, 2nd ed. W. H. Freeman and Co., New York.

VAN VALKENBURGH, B., AND F. HeRTEL. In press. The decline of North American predators during the Late Pleistocene. Illinois State Mus. Scientific Papers.

WAINWRIGHT, P. C. 1991. Ecomorphology: Experimental functional anatomy for ecological problems. Am. Zool. 31:680-693.

WARHEIT, K. I. 1992. The role of morphometrics and cladistics in the taxonomy of fossils: A paleornithological example. Syst. Biol. 41:345-369.

WILKINSON, L. 1988. SYSTAT: The system for statistics. SYSTAT, Inc., Evanston, Illinois.

WOODWARD, G. D., AND L. F. MARCUS. 1973. Rancho La Brea fossil deposits: A re-evaluation from stratigraphic and geological evidence. J. Paleontol. 47:54-69. 